\title{
The Connexin46 Mutant, Cx46T19M, Causes Loss of Gap Junction Function and Alters Hemi-channel Gating
}

\author{
Jun-Jie Tong $\cdot$ Peter J. Minogue $\cdot$ Matthew Kobeszko • \\ Eric C. Beyer • Viviana M. Berthoud • \\ Lisa Ebihara
}

Received: 5 August 2014/ Accepted: 7 November 2014/Published online: 18 November 2014

(C) The Author(s) 2014. This article is published with open access at Springerlink.com

\begin{abstract}
An N-terminal mutant of connexin46 (T19M) alters a highly conserved threonine and has been linked to autosomal dominant cataracts. To study the cellular and functional consequences of substitution of this amino acid, T19M was expressed in Xenopus oocytes and in HeLa cells. Unlike wild-type Cx46, T19M did not induce intercellular conductances in Xenopus oocytes. In transfected HeLa cells, T19M was largely localized within the cytoplasm, with drastically reduced formation of gap junction plaques. Expression of rat T19M was cytotoxic, as evidenced by an almost complete loss of viable cells expressing the mutant protein by $48-72 \mathrm{~h}$ following transfection. When incubated in medium containing physiological concentrations of divalent cations, T19Mexpressing cells showed increased uptake of DAPI as compared with cells expressing wild-type $\mathrm{Cx} 46$, suggesting aberrant connexin hemi-channel activity. Time-lapse and dye uptake studies suggested that T19M hemi-channels had reduced sensitivity to $\mathrm{Ca}^{2+}$. Whole cell patch clamp studies of single transfected HeLa cells demonstrated that rat T19M formed functional hemi-channels with altered voltage-dependent gating. These data suggest that T19M causes cataracts by loss of gap junctional channel function and
\end{abstract}

Electronic supplementary material The online version of this article (doi:10.1007/s00232-014-9752-y) contains supplementary material, which is available to authorized users.

J.-J. Tong · M. Kobeszko · L. Ebihara $(\bowtie)$

Department of Physiology and Biophysics, Chicago Medical

School, Rosalind Franklin University of Medicine and Science,

3333 Green Bay Road, North Chicago, IL 60064, USA

e-mail: lisa.ebihara@ rosalindfranklin.edu

P. J. Minogue · E. C. Beyer · V. M. Berthoud

Department of Pediatrics, University of Chicago,

900 E. 57th Street, Chicago, IL 60637, USA abnormally increased hemi-channel activity. Furthermore, they implicate this conserved threonine in both gap junction plaque formation and channel/hemi-channel gating in Cx46.

Keywords Cataract - Lens - Gap junction . Hemi-channel $\cdot$ Cx46

\section{Introduction}

Studies of mutants identified by linkage to diseases or by systematic site-directed mutagenesis are helping to clarify the function and regulation of channels and hemi-channels formed by connexins $(\mathrm{Cx})$. The connexins are a family of proteins that form gap junction plaques which contain intercellular channels that directly connect the cytoplasm of one cell with that of a neighbor. Gap junctional channels are formed by the docking of two hexameric connexin assemblies (connexons), contributed by the two communicating cells. Undocked connexons are also present in the non-junctional plasma membrane where they can act as transmembrane "hemi-channels" that are gated by extracellular divalent cations, intracellular concentrations of $\mathrm{Ca}^{2+}$ and $\mathrm{H}^{+}$, and voltage (Ebihara 2003; Sáez et al. 2010).

The connexin family contains 21 human members that share extensive sequence identity and similarity (Beyer and Berthoud 2009). All of the connexins have a similar transmembrane topology, containing four transmembrane domains with both the $\mathrm{N}$ - and $\mathrm{C}$-termini residing on the cytoplasmic side of the membrane. The $\mathrm{N}$-terminus makes a substantial contribution to the channel properties. Structural studies of another family member, Cx26, have shown that the $\mathrm{N}$-terminus inserts into the channel pore and forms a funnel (Maeda et al. 2009). Functional studies of several 
connexins indicate that alterations of charged residues in this domain affect channel gating and permeability (Dong et al. 2006; Oh et al. 2000, 2008; Purnick et al. 2000; Tong et al. 2004, 2013; Tong and Ebihara 2006; Verselis et al. 1994).

Connexin mutations have been linked to a variety of different pathologies including deafness, X-linked CharcotMarie-tooth disease, skin diseases, oculodentodigital dysplasia, and cataracts. Our laboratories have particularly focused on examining the cellular and physiological abnormalities caused by mutations of $\mathrm{Cx} 46$ and $\mathrm{Cx} 50$ that are associated with inherited congenital cataracts. These studies have identified various mechanisms by which the mutations lead to disease, including loss-of-function, gainof-(hemi-channel)-function, and dominant-negative inhibition of wild-type connexin function (Beyer et al. 2013).

The present study was designed to examine the cellular and physiological behavior of a recently identified Cx46 mutant that causes the replacement of the threonine at position 19 with methionine (T19M). This mutation was identified in members of a family of people who developed posterior cortical cataracts that were inherited in an autosomal dominant manner (Santhiya et al. 2010). Threonine19 is a residue that is nearly perfectly conserved in all members of the connexin family, implying the importance of this amino acid for connexin function. However, there have not been previous systematic studies of disease-linked substitutions at this position. Therefore, elucidation of the abnormalities conferred by this mutation may yield insights into the pathogenesis of inherited cataracts and diseases linked to other connexins mutated at this position.

The data presented below show that the T19M substitution results in alterations of gap junction channel and hemi-channel behaviors.

\section{Materials and Methods}

\section{Generation of $\mathrm{Cx} 46$ Constructs}

DNA segments encoding rat and human T19M were obtained by polymerase chain reaction (PCR) using oligonucleotide primers encoding the nucleotide substitution, Phusion high-fidelity DNA polymerase (New England Biolabs, Ipswich, MA) and plasmid templates containing wildtype human Cx46 in pSP64TII and pcDNA3.1/Hygro(+) (Invitrogen, Carlsbad, CA) or rat $\mathrm{Cx} 46$ in pBluescript (Stratagene, La Jolla, CA). Primers facing opposite directions (human Cx46T19M sense: TGGTCATCGGCAAGGT TTGGCTGACCGT and human Cx46T19M antisense: TGGAGTGCTCCTGTGCATTTTCTAAGAGTC; rat Cx46T19M sense: TGGTCATCGGCAAGGTGTGGCT GACCGTCC and rat Cx46T19M antisense: TAGAGTGCT
CCTGCGCATTCTCCAGCAGCC) and spanning the DNA region encoding the mutated amino acid were designed to amplify the sequence of the full construct (including the vector sequence) according to the strategy used previously (Minogue et al. 2005); the plasmids were regenerated by religation of the PCR product. Wild-type rat Cx46 and T19M were subsequently subcloned into pcDNA3.1(+) (Invitrogen) and PBI-CMV3 (Clontech). Rat Cx46T19M was subcloned into pSP64TII.

Plasmids were also produced that encoded human $\mathrm{Cx} 46$ or T19M fused to Enhanced Green Fluorescent Protein (EGFP), following a 19 amino acid linker sequence. The coding regions of human Cx46 or T19M were amplified by PCR using PfuTurbo DNA Polymerase (Stratagene) and sense primer: TCCGAATTCACTAGTGAGCCGCCATG GGCGACTGGAG, and antisense primer: CTAAGAATTC GATTTCCTCCGATGGCCAAGTCCTCCGG, then subcloned into the EcoRI site of the expression vector pEGFPN1 (Clontech Laboratories, Mountain View, CA).

The coding regions of all constructs were fully sequenced to ensure that PCR amplification did not introduce additional unwanted mutations.

\section{Cell Culture and Immunofluorescence}

For the immunofluorescence experiments, HeLa cells were plated on 4-well chamber slides (LAB TEK, Nalge Nunc International, Naperville, IL) or glass coverslips, and grown as previously described (Berthoud et al. 2003; Tong et al. 2013). The cells were transiently transfected with wild-type Cx46 or T19M using Lipofectin Transfection Reagent (Invitrogen) and PLUS Reagent (Invitrogen). Eighteen to $48 \mathrm{~h}$ later, cells were fixed in $4 \%$ paraformaldehyde. After fixation, cells were subjected to immunofluorescence using rabbit anti-Cx46 antibodies and Cy3conjugated goat anti-rabbit IgG antibodies (Jackson ImmunoResearch, West Grove, PA) as previously described (Minogue et al. 2005). Cells were examined using a Zeiss Plan Apochromat $40 \times$ objective (n.a., 1.0) in an Axioplan 2 microscope (Carl Zeiss Inc., München, Germany) equipped with a mercury lamp, and images were acquired with a Zeiss AxioCam digital camera and Zeiss AxioVision software (Carl Zeiss Inc.). Figures were assembled using Adobe Photoshop CS3 Extended (Adobe Systems Inc., San Jose, CA).

\section{Uptake of Connexin-Permeant Tracers}

The dye uptake experiments utilized a communicationdeficient clone of HeLa cells provided by V.K. Verselis (Albert Einstein College of Medicine, Bronx, NY). They were transfected with a bidirectional promoter vector, PBICMV3, encoding rat $\mathrm{Cx} 46$ or $\mathrm{T} 19 \mathrm{M}$ and the reporter 
protein, Zaza green, or human Cx46-EGFP or human T19M-EGFP using Happyfect (Mayflower Bioscience, St. Louis, MO). Cells were tested for dye uptake 1 day later by a 20-min exposure to sodium Ringer's solution $(150 \mathrm{mM}$ sodium gluconate or $\mathrm{NaCl}, 4.7 \mathrm{mM} \mathrm{KCl}, 5 \mathrm{mM}$ glucose, and $5 \mathrm{mM}$ HEPES, $\mathrm{pH}$ 7.4) with or without divalent cations and to which $10 \mu \mathrm{M}$ 4',6-diamino-2-phenylindole dihydrochloride (DAPI) was added. Then, cells were washed in the sodium Ringer's solution containing $1 \mathrm{mM} \mathrm{Ca}^{2+}$ and $1 \mathrm{mM} \mathrm{Mg}^{2+}$ without dyes and examined by epifluorescence using a Nikon Eclipse inverted microscope equipped with a CCD camera (Photometrics, Tucson, AZ) associated with image analysis software (NIS Elements AR 3.0, Nikon). Uptake of DAPI was quantified by placing a region of interest (ROI) over the nuclei of cells expressing the reporter protein and measuring the mean intensity of DAPI after correction for background fluorescence measured in a cell-free region. Two to five $20 \times$ fields of view were analyzed for each treatment to generate histograms of the intensity of DAPI in reporter proteinexpressing cells. Dead cells identified by morphological criteria were excluded from the data analysis.

Time-lapse experiments using rat $\mathrm{Cx} 46$ or T19M were performed using a closed bath insert (RC-37FC; Warner Instruments) as previously described (Ebihara et al. 2011). Four $\mu$ M DAPI was added to all of the perfusion solutions. The rate of DAPI uptake under control conditions, following removal of divalent cations, and after addition of $\mathrm{La}^{3+}$ was determined by fitting the time course of DAPI uptake to a linear regression.

\section{Expression of Connexins in Xenopus Oocytes}

Connexin cRNAs were synthesized using the mMessage mMachine in vitro transcription kit (Ambion, Austin, TX) according to the manufacturer's instructions. The amount of cRNA was quantitated by measuring the absorbance at $260 \mathrm{~nm}$.

Adult female Xenopus laevis frogs were anesthetized with tricaine and a partial ovariectomy was performed in accordance with protocols approved by the Animal Care and Use Committee at Rosalind Franklin University in North Chicago, IL. The oocytes were manually defolliculated after treating them with collagenase IA (Worthington Biochemical Corporation, Lakewood, NJ). Stage V and VI oocytes were selected and pressureinjected using a Nanoject variable microinjection apparatus (model No. 3-000-203, Drummond Scientific, Broomal, PA) with $36.8 \mathrm{nl}$ of $0.5-600 \mathrm{ng} / \mu \mathrm{l}$ of connexin cRNA and $5 \mathrm{ng} / 36.8 \mathrm{nl}$ of oligonucleotides antisense to mRNA for Xenopus Cx38 as previously described (Ebihara 1996). The oocytes were incubated overnight at
$18{ }^{\circ} \mathrm{C}$ in L-15 (GIBCO-Invitrogen, Carlsbad, CA) containing $2 \mathrm{mM} \mathrm{CaCl}_{2}$ prior to performing electrophysiological experiments.

\section{Electrophysiological Measurements}

For measurement of gap junctional coupling, connexin cRNA-injected oocytes were devitellinized and paired as previously described (Ebihara 1992). Double two-microelectrode voltage clamp experiments were performed using GeneClamp 500 (Molecular Devices, Sunnyvale, CA) and a TEV-200A (Dagan Corporation, MN) as previously described (Xu and Ebihara 1999). Pulse generation and data acquisition were performed using a PC computer equipped with PCLAMP9 software and a Digidata 1322A data acquisition system (Molecular Devices). All experiments were performed at room temperature $\left(20-22{ }^{\circ} \mathrm{C}\right)$.

Hemi-channel currents were recorded from single transfected HeLa cells using the whole cell variant of the patch clamp technique. The resistance of the patch pipettes was $2-4 \mathrm{M} \Omega$ when filled with standard internal solution. After rupturing the membrane patch, the series resistance was usually $<10 \mathrm{M} \Omega$ and was therefore not compensated. The internal solution contained: $140 \mathrm{mM} \mathrm{CsCl}, 10 \mathrm{mM}$ EGTA, $2 \mathrm{mM}$ MgATP, $3 \mathrm{mM} \mathrm{Na} \mathrm{N}_{2} \mathrm{ATP}, 10 \mathrm{mM}$ HEPES, $\mathrm{pH}$ 7.4. The standard external bath solution contained $150 \mathrm{mM}$ Na gluconate, $4.7 \mathrm{mM} \mathrm{KCl}, 1 \mathrm{mM} \mathrm{MgCl} 2,1 \mathrm{mM}$ $\mathrm{CaCl}_{2}, 5 \mathrm{mM}$ glucose, $5 \mathrm{mM}$ HEPES, $\mathrm{pH}$ 7.4. The membrane potentials were not corrected for liquid-junction potentials.

\section{Results}

We initially tested whether T19M was able to induce gap junctional (intercellular) conductances in paired Xenopus oocytes using the double two-electrode voltage clamp technique. Because rodent $\mathrm{Cx} 46$ induces higher levels of gap junctional currents than human $\mathrm{Cx} 46$ in this system, experiments were initially performed after injecting cRNAs encoding either wild-type or mutant rat $\mathrm{Cx} 46$. Homotypic oocyte pairs expressing wild-type rat $\mathrm{Cx} 46$ were well coupled, but oocyte pairs injected with rat T19M cRNA showed no coupling above control levels (Fig. 1a). Furthermore, oocytes expressing rat T19M failed to induce significant coupling when paired heterotypically with oocytes expressing wild-type Cx46 (Fig. 1a).

To determine if co-expression of T19M affected the junctional conductance produced by wild-type lens connexins, we tested pairs of oocytes co-injected with equal amounts of cRNAs encoding rat T19M and wild-type rat $\mathrm{Cx} 46$ or mouse $\mathrm{Cx} 50$. The conductances induced in oocyte pairs co-expressing T19M with wild-type Cx46 did not 

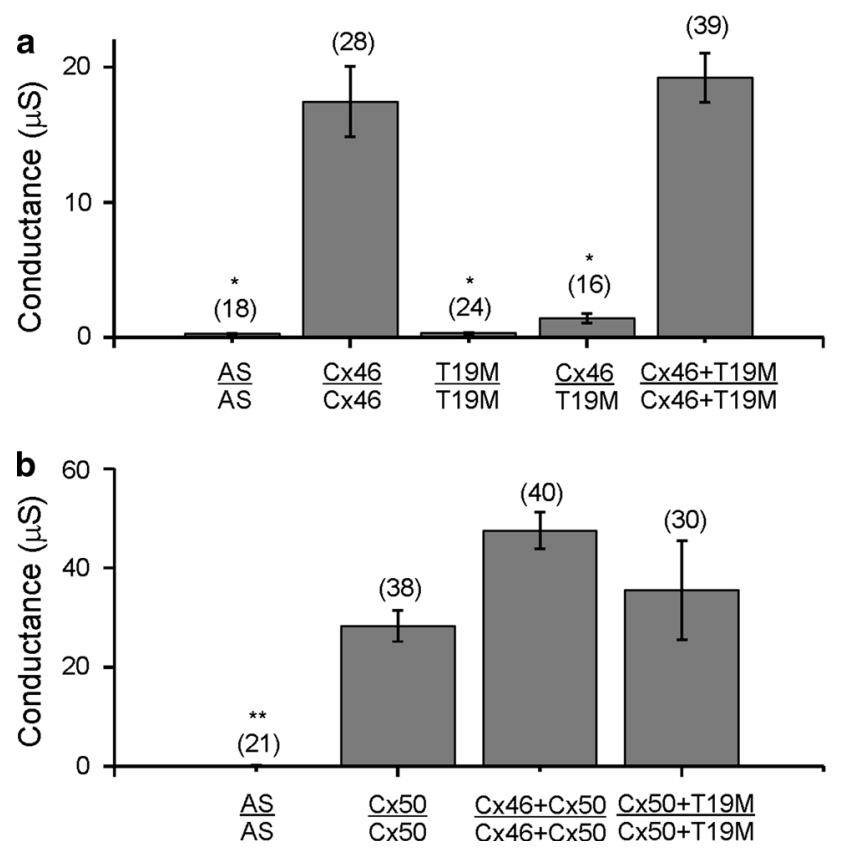

Fig. 1 T19M does not induce gap junctional coupling when expressed by itself, and it acts as a loss-of-function mutation without dominant-negative inhibition when co-expressed with wild-type lens connexins. Bar graphs show mean gap junctional conductances in pairs of oocytes expressing different combinations of wild-type and mutant lens connexins as determined using the double two-electrode voltage clamp technique. a Rat $\mathrm{Cx} 46$ or T19M were expressed alone or in combination with each other. b Mouse Cx50 was expressed alone or in combination with either rat $\mathrm{Cx} 46$ or T19M. AS indicates oocytes that were injected with no cRNA (i.e., Xenopus Cx38 antisense oligonucleotide alone). The number of pairs tested is indicated within parentheses. ${ }^{*} p<0.001$ (Student's $t$ test compared with Cx46-injected oocyte pairs); $* * p<0.001$ (Student's $t$ test compared with $\mathrm{Cx} 50$-injected oocyte pairs)

differ significantly from those expressing only wild-type Cx46 (Fig. 1a). Similarly, the conductances induced in oocyte pairs co-expressing T19M with Cx50 did not differ significantly from those expressing $\mathrm{Cx} 50$ alone or those coexpressing wild-type Cx50 and wild-type Cx46 (Fig. 1b). These results suggest that $\mathrm{T} 19 \mathrm{M}$ acts as a loss-of-function mutation without dominant-negative inhibition of intercellular communication.

To determine the ability of T19M to form gap junction plaques, we performed immunofluorescence staining on transiently transfected HeLa cells. Cells transfected with wild-type rat $\mathrm{Cx} 46$ showed strong staining at gap junction plaques and some staining in the perinuclear region, likely corresponding to the Golgi apparatus (Fig. 2a). Surprisingly, in multiple independent experiments we detected very few cells containing immunoreactive Cx46 after transfection with rat $\mathrm{T} 19 \mathrm{M}$ at our usual time of observation $(48 \mathrm{~h})$. Eighteen hours following transfection, most Cx46T19M-expressing cells showed a normal morphology with strong perinuclear staining and no gap junctional plaques (Fig. 2b). By $24 \mathrm{~h}$ after transfection, cells had started to round up and the abundance of cells expressing the Cx46 mutant was decreased (Fig. 2c). After 48-72 h, cells showed low intensity of Cx46T19M immunoreactivity, lacked detectable gap junctions, and were rounded up (Fig. 2d). The striking decline in numbers of T19Mexpressing cells and their rounded morphology suggested that the mutated protein had toxic effects.

To assess the potential toxicity of T19M, we quantified the proportion of rounded up Zaza-green positive cells (expressed with the connexin using the bidirectional promoter vector, PBI-CMV3) after transfection. For these experiments, we used a different transfection reagent (Happyfect), because it has been reported to be less toxic to cultured cells. Seventy-two hours after transfection, $89 \%$ (149/167) of the T19M transfected cells were rounded up as compared to only $14 \%$ (21/126) of the wild-type Cx46 and $16 \%(51 / 318)$ of vector-transfected cells. The morphology of the cells expressing T19M was strikingly different from that of the cells expressing wild-type $\mathrm{Cx} 46$ as illustrated in Fig. S1. In addition to rounding up, many of the T19M expressing cells showed extensive membrane blebbing which is often seen in dying cells.

To test the hypothesis that the apparent cell toxicity in T19M-expressing cells was a consequence of aberrant T19M hemi-channel activity, we examined uptake of the connexon-permeant dye, DAPI, in transfected HeLa cells. Cells that expressed rat $\mathrm{Cx} 46$ or $\mathrm{T} 19 \mathrm{M}$ were identified by the fluorescence of the reporter protein, Zaza green (Fig. 3). When incubated in the absence of divalent cations or in the presence of $1 \mathrm{mM}$ external $\mathrm{Ca}^{2+}$ concentration $\left(\left[\mathrm{Ca}^{2+}\right]_{\mathrm{o}}\right.$ and $\left.1 \mathrm{mM}\left[\mathrm{Mg}^{2+}\right]_{\mathrm{o}}\right)$, cells expressing $\mathrm{T} 19 \mathrm{M}$ showed significantly increased DAPI uptake compared to cells expressing wild-type Cx46 or control (Zaza-green negative) cells. The T19M-induced dye uptake was mostly blocked by increasing the $\left[\mathrm{Ca}^{+2}\right]_{\mathrm{o}}$ to $5 \mathrm{mM}$.

In some experiments, we used propidium iodide (PI) and DAPI as the connexon-permeant tracers (data not shown). These experiments showed a linear relationship between the rates of DAPI and PI uptake. However, the rate of PI uptake was much smaller than the rate of DAPI uptake.

To examine the effect of wild-type and mutant $\mathrm{Cx} 46$ on hemi-channel activity in greater detail, we measured the uptake of DAPI by time-lapse recordings in HeLa cells expressing wild-type rat $\mathrm{Cx} 46, \mathrm{~T} 19 \mathrm{M}$, or vector alone (Fig. 4). In the presence of control external solution (containing $1 \mathrm{mM} \mathrm{Ca}^{2+}$ and $1 \mathrm{mM} \mathrm{Mg}^{2+}$ ), cells expressing T19M showed significantly higher rates of DAPI uptake than those expressing wild-type $\mathrm{Cx} 46$ or vector alone. After changing the bathing medium to a solution free of divalent cations, the rate of DAPI uptake increased by approximately twofold in the T19M cells and by up to 19-fold in the Cx46 cells. Little or no increase in dye 


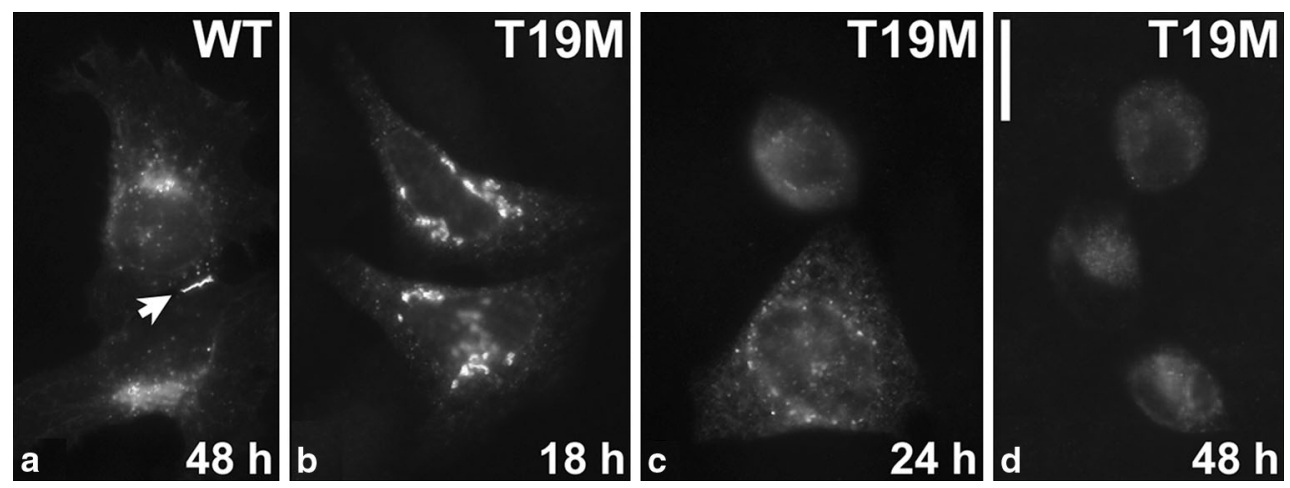

Fig. 2 T19M is inefficient at forming gap junction plaques. Photomicrographs show the distribution of wild-type rat Cx46 (a) and T19M (bd) at the indicated times following transient transfection of HeLa cells. Bar $30 \mu \mathrm{M}$

Fig. 3 T19M causes increased uptake of connexon-permeant dyes. Photomicrographs show examples of HeLa cells that were transfected with wild-type rat $\mathrm{Cx} 46(\mathbf{a}-\mathbf{c})$ or T19M $(\mathbf{d}-\mathbf{i})$ (using the vector PBI-CMV3 which also drives expression of Zaza green) and incubated a day later with DAPI in Na gluconate Ringer's solution containing $0 \mathrm{mM} \mathrm{Ca}^{2+}(\mathbf{a}-\mathbf{f})$ or $5 \mathrm{mM}$ $\mathrm{Ca}^{+2}(\mathbf{g}-\mathbf{i})$ for $20 \mathrm{~min}$. Phase contrast images $(\mathbf{a}, \mathbf{d}, \mathbf{g})$. Zazagreen fluorescence $(\mathbf{b}, \mathbf{e}, \mathbf{h})$. DAPI fluorescence $(\mathbf{c}, \mathbf{f}, \mathbf{i})$. After a 20-min incubation in control solution containing $0 \mathrm{mM} \mathrm{Ca}{ }^{2+}$, cells expressing T19M showed DAPI uptake (e, f) that was mostly inhibited by $5 \mathrm{mM} \mathrm{Ca}^{2+}(\mathbf{h}, \mathbf{i})$. Bar graph summarizes the quantification of the DAPI uptake data (j).

Data are graphed as mean \pm SEM. The number of cells tested is indicated within parentheses. $* p<0.001$ (Mann-Whitney rank sum test compared with wild-type rat Cx46-transfected cells)

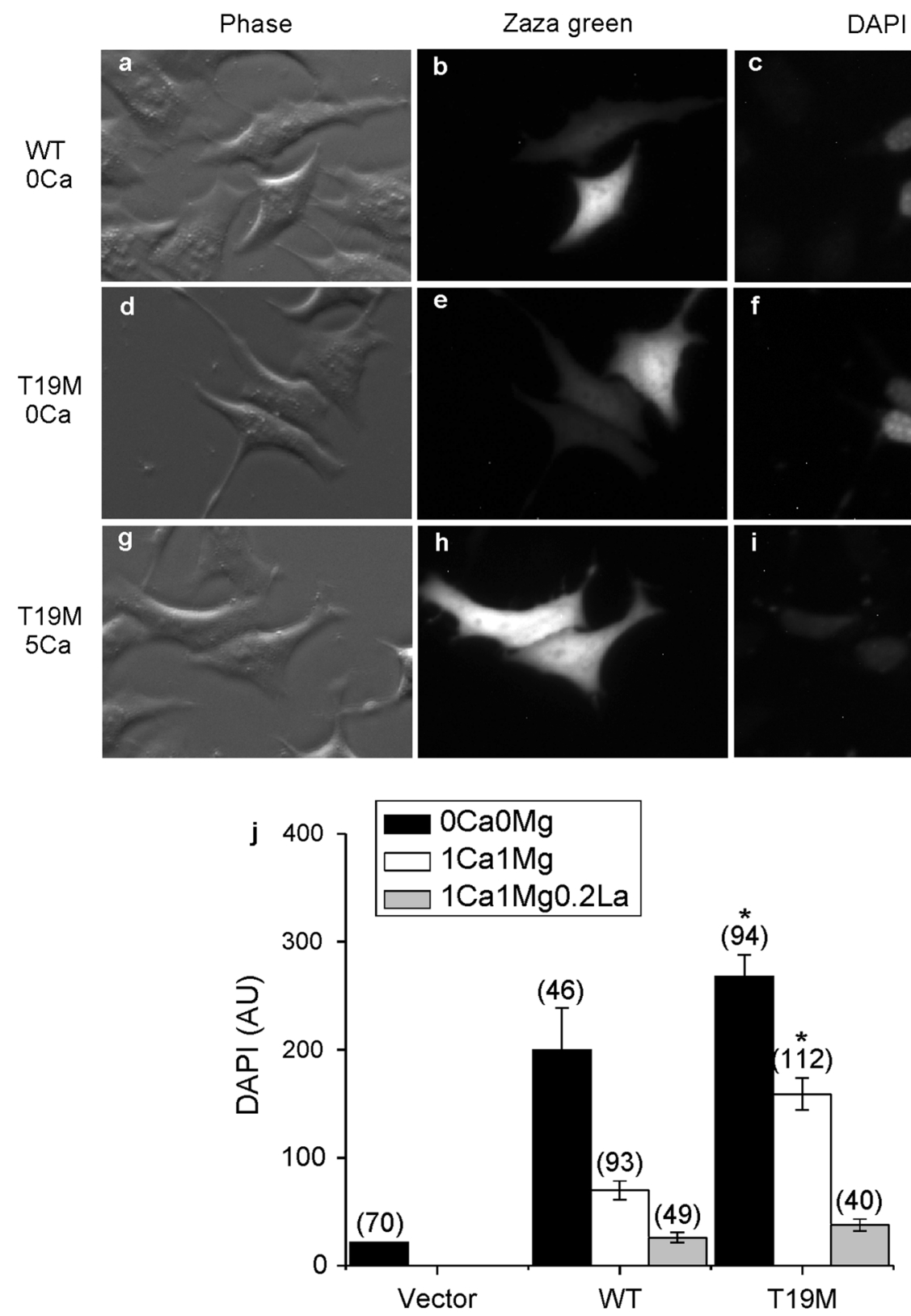




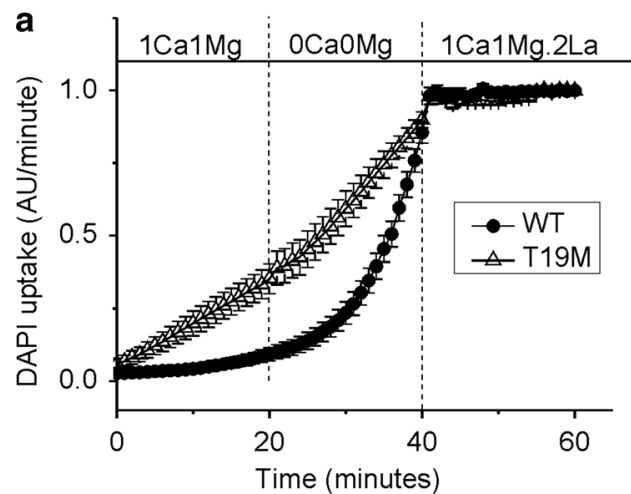

Fig. 4 The rate of DAPI uptake is increased by lowering divalent cations and inhibited by $\mathrm{La}^{3+}$. Average time course of DAPI uptake by transfected HeLa cells in control solution $\left(1 \mathrm{mM} \mathrm{Ca}^{2+}\right.$, $1 \mathrm{mM} \mathrm{Mg}^{2+}$ ), in external solutions with no added divalent cations and in control solution plus $200 \mu \mathrm{M} \mathrm{La}^{3+}$. a Wild-type rat $\mathrm{Cx} 46$ (closed circles); T19M (open triangles). To measure changes in the rate of dye uptake over time, the mean DAPI fluorescence intensity per pixel from ROI's located in the nuclei of Zaza-green positive cells were normalized to mean DAPI fluorescence intensity of the ROI's at $60 \mathrm{~min}$, averaged and plotted as a function of time. The cells were initially bathed in control solution (containing $1 \mathrm{mM} \mathrm{Ca}^{2+}$,

uptake was observed in control cells expressing vector alone (data not shown). Dye uptake was completely blocked by application of $200 \mu \mathrm{M}$ lanthanum, a nonspecific connexin hemi-channel blocker. Dye uptake was also $\sim 90 \%$ blocked in Cx46 cells and $77 \%$ blocked in T19M cells by application of $500 \mu \mathrm{M}$ carbenoxolone. These results suggest that the $\mathrm{T} 19 \mathrm{M}$ channels are less sensitive to blockade by divalent cations than wild-type $\mathrm{Cx} 46$ hemichannels. Interestingly, the effect of divalent cation-free conditions on the wild-type $\mathrm{Cx} 46$ cells was slow, requiring greater than $15 \mathrm{~min}$ to reach a new steady-state. In contrast, the effect of divalent cation-free conditions on the T19M cells was relatively fast, reaching steady-state in $<2 \mathrm{~min}$.

To determine the effects of T19M on plasma membrane conductance of HeLa cells, whole cell patch clamp experiments were performed with cesium in the pipette and sodium in the bath. Figure 5 compares representative families of current traces (and averaged steady-state I-V relationships) recorded from HeLa cells expressing Cx46, $\mathrm{T} 19 \mathrm{M}$, or Zaza green alone in the presence of $1 \mathrm{mM}$ $\left[\mathrm{Ca}^{+2}\right]_{\mathrm{o}}$ and $1 \mathrm{mM}\left[\mathrm{Mg}^{+2}\right]_{\mathrm{o}}$. Both Cx46- and T19Mexpressing cells exhibited currents that were mostly closed at $-60 \mathrm{mV}$ and activated in response to depolarizing voltage clamp steps in a time- and voltage-dependent manner. These currents were not observed in either nontransfected cells or Zaza-green-transfected cells, indicating that they could be attributed to Cx46 and T19M hemichannels. Both wild-type and mutant currents could be readily observed in cells transfected with similar amounts of DNA even when the bath solution contained $1 \mathrm{mM} \mathrm{Ca}^{2+}$ (and $1 \mathrm{mM} \mathrm{Mg}^{2+}$ ). However, the $\mathrm{T} 19 \mathrm{M}$ mutation altered

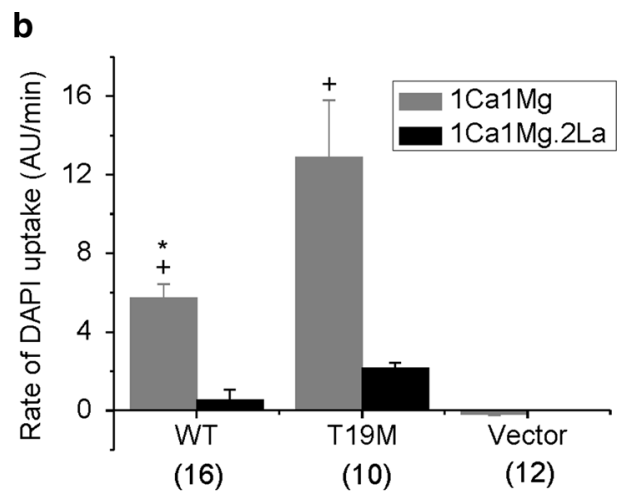

$\left.1 \mathrm{mM} \mathrm{Mg}^{2+}\right)$. Then, the cells were exposed to a solution containing no added divalent cations followed by reperfusion with control solution containing $200 \mu \mathrm{M} \mathrm{La}^{3+}$. All the solutions contained $4 \mu \mathrm{M}$ DAPI. b Bar graph shows the rates of DAPI uptake in cells expressing wild-type $\mathrm{Cx} 46, \mathrm{~T} 19 \mathrm{M}$, or vector alone in the presence of $1 \mathrm{mM} \mathrm{Ca}^{2+}, 1 \mathrm{mM} \mathrm{Mg}^{2+}$ (gray bar); or $1 \mathrm{mM} \mathrm{Ca}^{2+}, 1 \mathrm{mM} \mathrm{Mg}^{2+}$, $0.2 \mathrm{mM} \mathrm{La}^{3+}$ (black bar). Data are presented as the mean $\pm \mathrm{SEM}$. $* p<0.002$ (Mann-Whitney rank sum test compared with T19Mtransfected cells); ${ }^{+} p<0.001$ (Mann-Whitney rank sum test compared with vector-transfected cells). The number of cells analyzed is indicated within parentheses

the kinetics of channel gating. T19M currents activated more rapidly and had a more pronounced and prolonged inactivation phase than the wild-type $\mathrm{Cx} 46$ currents at large positive potentials as illustrated in Fig. $6 \mathrm{a}$ and b. In addition, the time course of deactivation of the T19M currents at negative potentials was slower than that of wild-type $\mathrm{Cx} 46$. This effect was quantified by measuring the time required for the tail current to decay to $50 \%$ of its peak value $\left(t_{1 / 2}\right)$. Over the transmembrane voltage $\left(V_{\mathrm{m}}\right)$ range between -80 and $-40 \mathrm{mV}$, the average $t_{1 / 2}$ values were significantly longer for T19M than for wild-type Cx46 (Fig. 6d). This effect did not appear to correlate with changes in current density since the amplitudes of the T19M tail currents used in the data analysis were smaller than those of the WT tail currents (Fig. 6c).

To determine if the small, persistent inward current observed at negative potentials in T19M-expressing cells was due to hemi-channels, we used the nonspecific hemichannel blocker, $\mathrm{La}^{+3}$ (John et al. 1999; Contreras et al. 2002). Application of $200 \mu \mathrm{M} \mathrm{La}^{3+}$ blocked most of the time- and voltage-dependent component of the current (Fig. 7). It also reduced the inward current at the holding potential and decreased the cell input conductance to values comparable to those observed in vector-transfected control cells. Similar results were obtained for wild-type Cx46. The Cx46 hemi-channel currents could also be partially blocked by $200 \mu \mathrm{M}$ carbenoxolone. These findings suggest that a small number of $\mathrm{Cx} 46$ hemi-channels remain open even in the presence of divalent cations and that these channels can account for the dye uptake observed in the presence of divalent cations. 


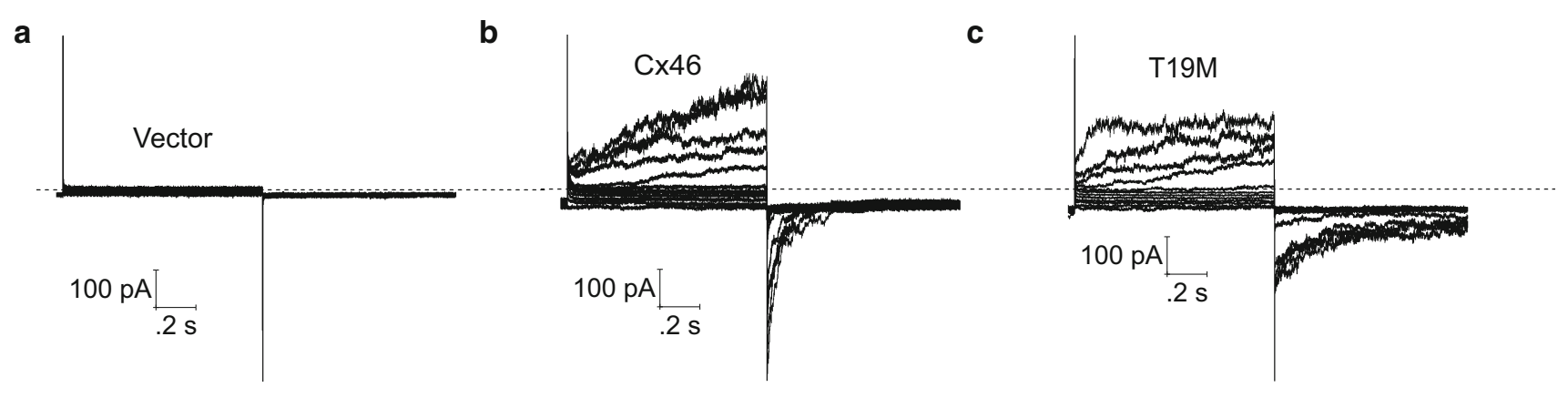

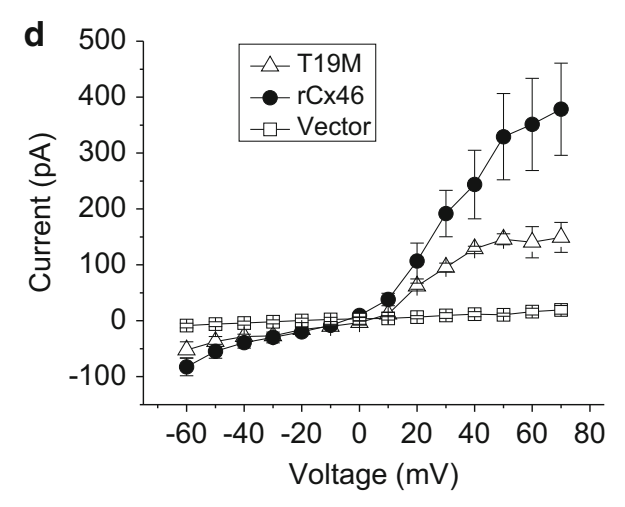

Fig. 5 Representative families of current traces recorded from single HeLa cells transfected with vector alone (a), wild-type rat Cx46 (b), or T19M (c). Families of current traces were recorded in response to a series of voltage clamp steps between -60 and $50 \mathrm{mV}$ in increments

Because the T19M was originally identified in a human family (Santhiya et al. 2010), we investigated whether human wild-type $\mathrm{Cx} 46$ and $\mathrm{T} 19 \mathrm{M}$ behaved similarly. Indeed, wild-type human Cx46 localized extensively to gap junction plaques with some localization in the cytoplasm in transfected HeLa cells (Fig. 8a). In contrast, human T19M immunoreactivity was detected mainly in intracellular compartments; on very rare occasions a faint staining at appositional membranes was detected (Fig. 8b).

Similar to the results obtained with the rat constructs, HeLa cells expressing human T19M-EGFP showed much higher rates of DAPI uptake in the presence of control external solutions (containing $1 \mathrm{mM} \mathrm{Ca}^{2+}$ and $1 \mathrm{mM} \mathrm{Mg}^{2+}$ ) than cells expressing wild-type $\mathrm{Cx} 46$ (Fig. 8c). The dye uptake in cells expressing either human $\mathrm{Cx} 46$ or T19M was completely blocked by application of $200 \mu \mathrm{MLa}^{3+}$ (Fig. 8c).

Thus, the T19M mutation disrupted gap junctional plaque formation and extracellular divalent cation-dependent regulation of hemi-channel gating regardless of the species of origin of the $\mathrm{Cx} 46$.

\section{Discussion}

In this paper, we have shown that mutation of the conserved threonine-19 to methionine causes a unique of $10 \mathrm{mV}$ from a holding potential of $-60 \mathrm{mV}$. Dashed line indicates zero current level. d Average steady-state I-V relationships for vector alone (open squares, $n=5$ ), wild-type (solid circles, $n=4$ ), and $\mathrm{T} 19 \mathrm{M}$ (open triangles, $n=3$ )

spectrum of alterations of connexin behavior. This residue is important for both cell biological and physiological functions, since Cx46T19M exhibits impaired gap junction assembly and abnormal gap junctional channel and hemichannel activities.

The inability of T19M to support intercellular communication is likely due to its poor formation of gap junction plaques. The absence of gap junctions could potentially result from altered trafficking of the connexin or reduced assembly of connexons into immunodetectable gap junction plaques. The detection of T19M hemi-channel activity by electrophysiology and dye uptake implies that the mutant forms oligomers that traffic properly to the plasma membrane. Therefore, the most likely explanation is that the mutant protein is inefficient at assembling into gap junction plaques. Several other connexin mutants that cause cataracts (including $\mathrm{Cx} 50 \mathrm{D} 47 \mathrm{~N}$ and Cx50R23T) (Arora et al. 2008; Thomas et al. 2008) or other diseases (Di et al. 2002; Marziano et al. 2003; VanSlyke et al. 2000) lack gap junction function because of inefficient formation of gap junction plaques ascribed to impaired trafficking of the connexin. In contrast, T19M has impaired formation of gap junction plaques, but it can traffic to the plasma membrane.

In our studies, T19M did not cause significant inhibition of co-expressed wild-type $\mathrm{Cx} 46$ or $\mathrm{Cx} 50$ gap junction 

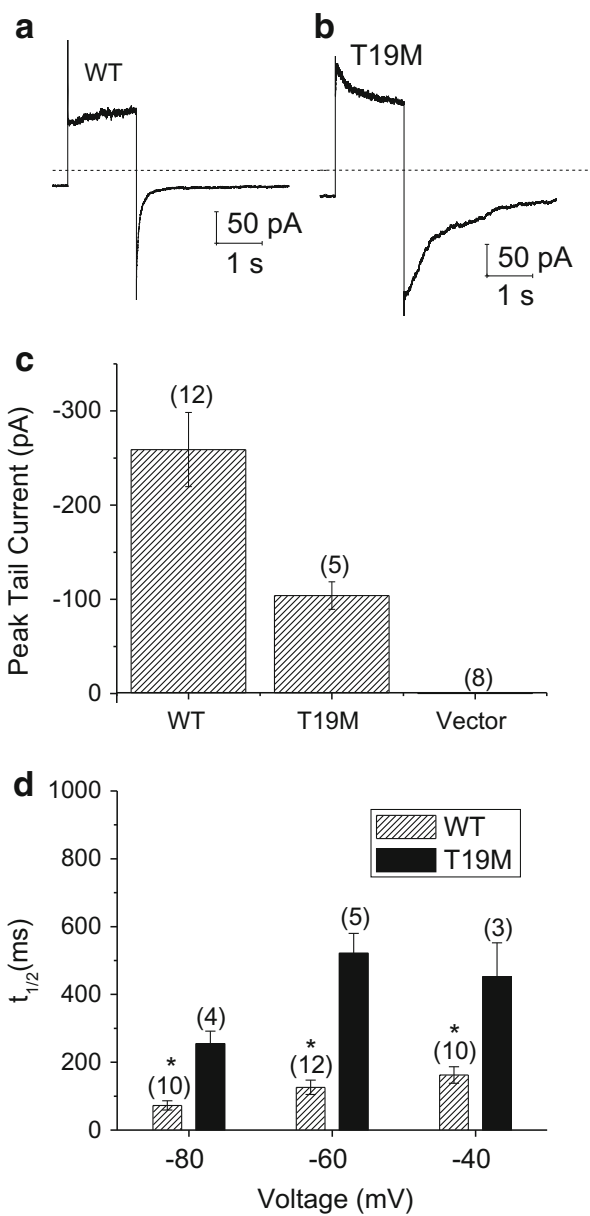

Fig. 6 T19M hemi-channels show alterations in voltage gating. Ensemble averaged current traces recorded from cells expressing wild-type rat $\mathrm{Cx} 46$ (a) or T19M (b) in response to a 2-s voltage clamp step to $80 \mathrm{mV}$ followed by a hyperpolarizing step to $-60 \mathrm{mV}$. The holding potential was $-60 \mathrm{mV}$. Dashed line indicates zero current level. c Averaged peak tail currents at $-60 \mathrm{mV}$. The number of cells tested is indicated within parentheses. d Bar graph summarizes the $t_{1 / 2}$ 's of deactivation of peak tail currents for wild-type rat $\mathrm{Cx} 46$ (hatched bars) and T19M (black bars) at $-80,-60$, and $-40 \mathrm{mV}$. Data are graphed as mean \pm SEM. ${ }^{*} p<0.01$ (Student's $t$ test or Mann-Whitney rank sum test compared with T19M-transfected cells). The number of cells analyzed is indicated within parentheses

activity. This loss-of-function behavior for gap junctional intercellular communication is similar to that reported for some other cataract-linked connexin mutants (e.g., Cx50D47N, Cx46N63S, Cx46fs380) (Arora et al. 2008; Pal et al. 2000), but contrasts with the dominant-negative effect induced by other mutants (e.g., Cx50P88S, Cx50P88Q) (Arora et al. 2006; Pal et al. 1999). The behavior of T19M suggests that either it does not cooligomerize with wild-type $\mathrm{Cx} 46$ or $\mathrm{Cx} 50$ or that its presence in mixed gap junction channels has no significant effect on function.
T19M also showed enhanced hemi-channel activity in the presence of physiological concentrations of divalent cations. A "gain of hemi-channel function" has been reported for some cataract-associated connexin mutants including Cx50G46V (Minogue et al. 2009; Tong et al. 2013) and Cx46G143R (Ren et al. 2013); however, unlike Cx46T19M, these mutants form gap junction plaques and support high levels of intercellular communication. A few $\mathrm{Cx} 43$ mutants that form non-functional gap junction plaques have been reported to form functional hemi-channels based on ATP release (Dobrowolski et al. 2007). Some Cx26 mutants associated with keratitis-ichthyosis-deafness syndrome display increased hemi-channel activity, but do not form gap junction plaques (Mhaske et al. 2013). There are a number of possible mechanisms that could lead to increased hemichannel activity. In the case of T19M, the impaired hemi-channel closing at negative potentials and the reduced sensitivity to external calcium implies that dysregulation of T19M hemi-channel gating (loop gating; Bukauskas et al. 1995) is the mechanism responsible for increased hemi-channel activity. Even the presence of a few functional T19M hemi-channels on the cell surface might be sufficient to account for the increase in hemichannel activity.

Previous studies have shown that the $\mathrm{N}$-terminus of Cx46 contributes to the pore lining and plays a critical role in channel gating (Kronengold et al. 2003; Tong and Ebihara 2006; Trexler et al. 2000). Homology models of Cx46 based on the crystal structure of Cx26 indicate that residue T19 lies on the cytoplasmic side of $\mathrm{Cx} 46$ near the hinge region where the $\mathrm{N}$-terminus bends into the pore. Replacement of $\mathrm{R} 9$ in the $\mathrm{N}$-terminus of the chicken ortholog of $\mathrm{Cx} 46$ changes voltage-dependent hemi-channel gating or loop gating (Tong and Ebihara 2006). Replacement of T19 by methionine may cause long distance conformational changes in the more proximal portion of the $\mathrm{N}$-terminus resulting in alterations in channel gating. Long-range conformational changes might affect the extracellular loops, because these regions are important for processes that are altered in the T19M mutant including loop gating and hemi-channel docking.

The various defects in $\mathrm{Cx} 46$ function caused by the T19M mutation may all contribute to the development of cataracts in people expressing the mutant and the dominant inheritance pattern. Homeostasis in the lens is normally supported by a circulation of water and ions that requires gap junction intercellular communication (Mathias et al. 2010). Because absence of one wild-type $\mathrm{Cx} 46$ allele in heterozygous mice decreases coupling conductance by $25 \%$ in differentiating fiber cells and by 
a
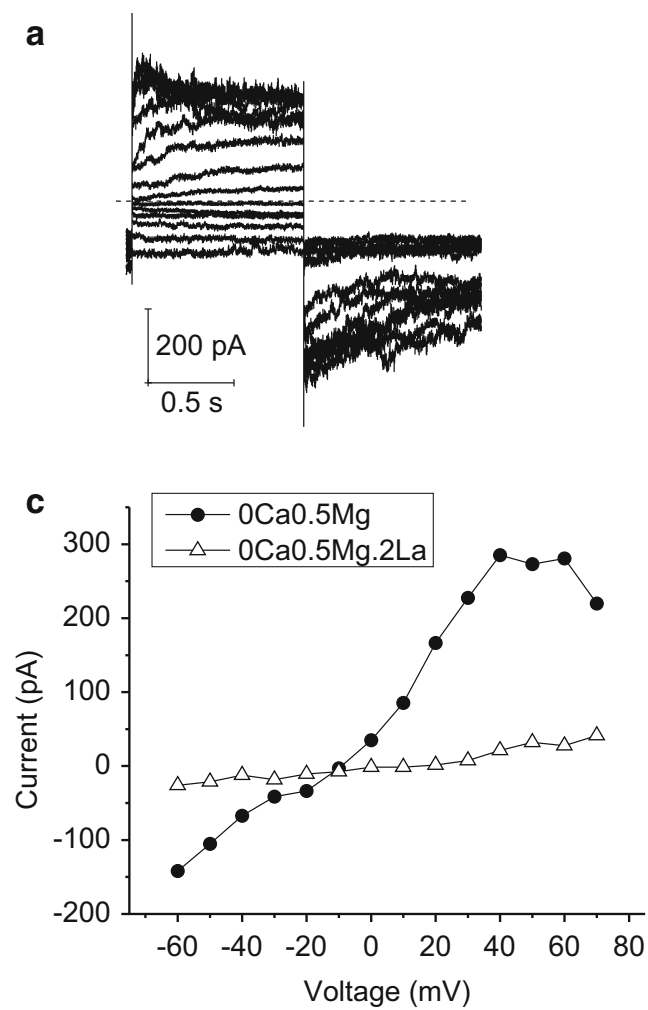

Fig. 7 Effect of lanthanum ions. Currents before (a) and after the application of $\mathrm{La}^{3+}(\mathbf{b} ; 200 \mu \mathrm{M})$ recorded from a HeLa cell expressing T19M. Families of current traces were recorded in response to a series of voltage clamp steps between -60 and $70 \mathrm{mV}$ in increments of $10 \mathrm{mV}$ from a holding potential of $-60 \mathrm{mV}$. Dashed line indicates zero current level. c I-V relations obtained from the data shown in $(\mathbf{a}, \mathbf{b})$. The current was measured at the end of the 1-s pulse and plotted as a function of voltage. The concentrations

$50 \%$ in mature fiber cells (Mathias et al. 2010), expression of T19M in the lens is expected to cause a reduction in the gap junction-mediated efflux of water, ions, and other solutes to the surface of the lens. However, haplodeficiency for a lens fiber connexin is not sufficient to cause cataracts in Cx46- and Cx50-null mice (Gong et al. 1997; Rong et al. 2002; White et al. 1998). Thus, it is likely that additional toxic effects contribute to the pathogenicity of $\mathrm{T} 19 \mathrm{M}$ in people and underlie the dominant inheritance of cataracts, most likely through the gain of hemi-channel activity. This would cause an increased influx of sodium and calcium into the fiber cells, contributing to their intracellular accumulation (especially since their efflux to the surface of the lens through a pathway involving gap junctions is reduced). These alterations could lead to the loss of metabolic homeostasis, activation of various enzymes (including proteases), and cataract formation. The cataracts in
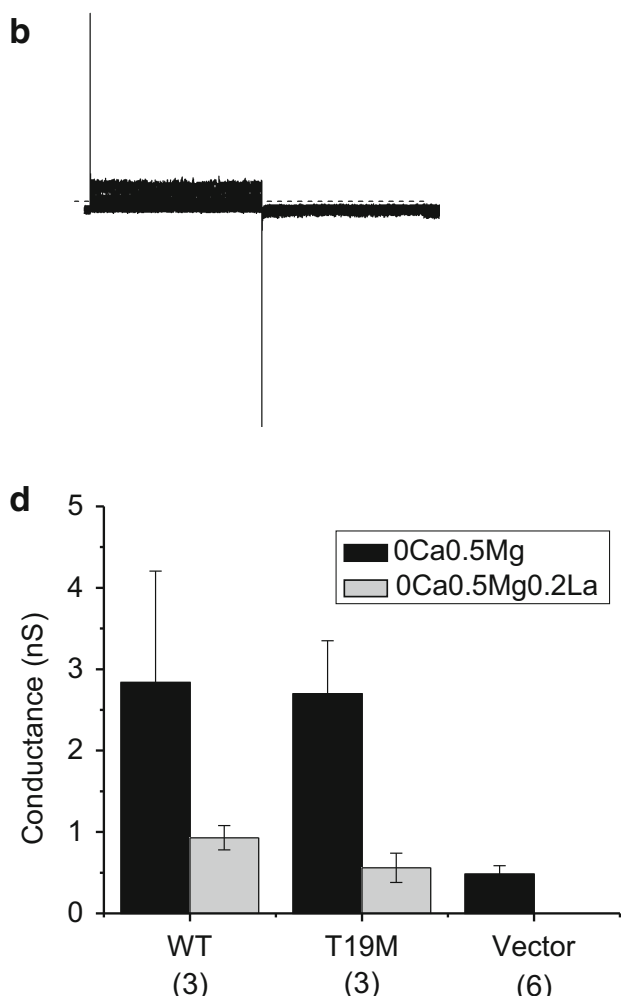

of divalent cations in the bath solution were reduced to zero added $\mathrm{Ca}^{2+}$ and $0.5 \mathrm{mM} \mathrm{Mg}^{2+}$ to augment the size of the hemi-channel currents. d Bar graph summarizes the input conductance measured at $-60 \mathrm{mV}$ in HeLa cells expressing wild-type Cx46, T19M, or vector (alone) when exposed to extracellular solutions containing $0 \mathrm{mM}$ $\mathrm{Ca}^{2+}, 0.5 \mathrm{mM} \mathrm{Mg}^{2+}$ (black bars) or $0 \mathrm{mM} \mathrm{Ca}{ }^{2+}, 0.5 \mathrm{mM} \mathrm{Mg}{ }^{2+}$, $0.2 \mathrm{mM} \mathrm{La}^{3+}$ (gray bars). The number of cells analyzed is indicated within parentheses

people carrying CX46T19M were described as "posterior polar" (Santhiya et al. 2010). Unfortunately, the mechanism for development of this type of cataract is not currently understood (Kalantan 2012). Moreover, there is no clear relationship between a specific lens connexin mutation and the cataract phenotype; indeed, the same mutation can produce cataracts with different appearances (reviewed in Beyer et al. 2013).

In conclusion, our data show that the $\mathrm{Cx} 46$ mutation, $\mathrm{T} 19 \mathrm{M}$, is inefficient at forming gap junction plaques, does not induce intercellular communication, and causes increased hemi-channel activity. This rather unique spectrum of defects demonstrates that T19 is a critical amino acid within the $\mathrm{N}$-terminus of $\mathrm{Cx} 46$. Because the identity of this amino acid is highly conserved among connexin subtypes, it is likely that mutations at this position would also affect the function of other connexins and contribute to disease in other tissues. 

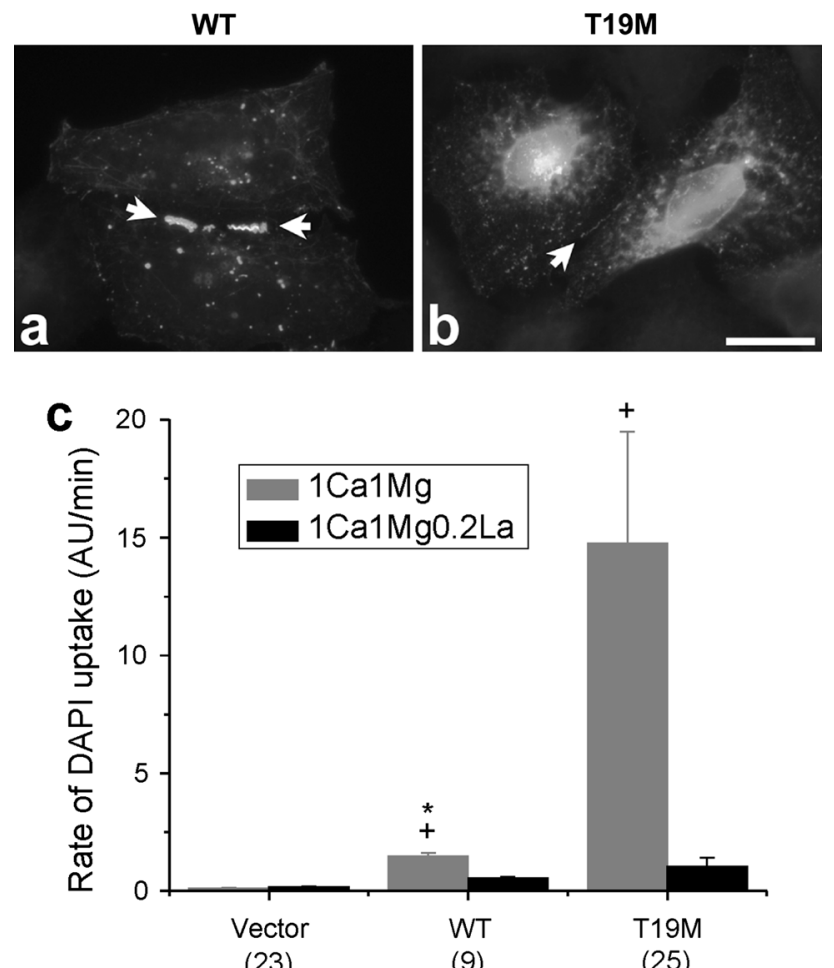

(23)

(9)

Fig. 8 Effects of T19M mutation on human Cx46. Photomicrographs showing the distribution of human wild-type $\mathrm{Cx} 46$ (a) and T19M (b) in transfected HeLa cells. Bar $30 \mu \mathrm{m}$. c Bar graph summarizes the DAPI uptake data for vector alone, human wild-type Cx46 and T19M obtained in transfected HeLa cells when exposed to extracellular solutions containing $1 \mathrm{mM} \mathrm{Ca}^{2+}, 1 \mathrm{mM} \mathrm{Mg}^{2+}$ (gray bars) or $1 \mathrm{mM}$ $\mathrm{Ca}^{2+}, 1 \mathrm{mM} \mathrm{Mg}^{2+}, 0.2 \mathrm{mM} \mathrm{La}^{3+}$ (black bars). Data are graphed as mean \pm SEM. ${ }^{*} p<0.004$ (Mann-Whitney rank sum test compared with T19M-transfected cells in the same external solution); ${ }^{+} p<0.001$ (Mann-Whitney rank sum test compared with vectortransfected cells). The number of cells analyzed is indicated within parentheses

Acknowledgment This work was supported by National Institute of Health Grant RO1 EY10589 (LE) and R01 EY08368 (ECB).

\section{Conflict of interest None.}

Open Access This article is distributed under the terms of the Creative Commons Attribution License which permits any use, distribution, and reproduction in any medium, provided the original author(s) and the source are credited.

\section{References}

Arora A, Minogue PJ, Liu X, Reddy MA, Ainsworth JR, Bhattacharya SS, Webster AR, Hunt DM, Ebihara L, Moore AT, Beyer EC, Berthoud VM (2006) A novel GJA8 mutation is associated with autosomal dominant lamellar pulverulent cataract: further evidence for gap junction dysfunction in human cataract. J Med Genet 43:e2. doi:10.1136/jmg.2005.034108

Arora A, Minogue PJ, Liu X, Addison PK, Russel-Eggitt I, Webster AR, Hunt DM, Ebihara L, Beyer EC, Berthoud VM, Moore AT

(2008) A novel connexin50 mutation associated with congenital nuclear pulverulent cataracts. J Med Genet 45:155-160. doi:10. 1136/jmg.2007.051029

Berthoud VM, Minogue PJ, Guo J, Williamson EK, Xu X, Ebihara L, Beyer EC (2003) Loss of function and impaired degradation of a cataract-associated mutant connexin50. Eur J Cell Biol 82:209-221. doi:10.1078/0171-9335-00316

Beyer EC, Berthoud VM (2009) The family of connexin genes. In: Harris AL, Locke D (eds) Connexins: a guide. Humana Press, New York, pp 3-26

Beyer EC, Ebihara L, Berthoud VM (2013) Connexin mutants and cataracts. Front Pharmacol 4:43. doi:10.3389/fphar.2013.00043

Bukauskas FF, Elfgang C, Willecke K, Weingart R (1995) Biophysical properties of gap junction channels formed by mouse connexin40 in induced pairs of transfected human HeLa cells. Biophys J 68:2289-2298. doi:10.1016/S0006-3495(95)80411-X

Contreras JE, Sanchez HA, Eugenin EA, Speidel D, Theis M, Willecke K, Bukauskas FF, Bennett MV, Saez JC (2002) Metabolic inhibition induces opening of unapposed connexin 43 gap junction hemichannels and reduces gap junctional communication in cortical astrocytes in culture. Proc Natl Acad Sci USA 99:495-500

Di WL, Monypenny J, Common JE, Kennedy CT, Holland KA, Leigh IM, Rugg EL, Zicha D, Kelsell DP (2002) Defective trafficking and cell death is characteristic of skin disease-associated connexin 31 mutations. Hum Mol Genet 11:2005-2014. doi:10.1093/hmg/11.17.2005

Dobrowolski R, Sommershof A, Willecke K (2007) Some oculodentodigital dysplasia-associated $\mathrm{Cx} 43$ mutations cause increased hemichannel activity in addition to deficient gap junction channels. J Membr Biol 219:9-17. doi:10.1007/s00232-0079055-7

Dong L, Liu X, Li H, Vertel BM, Ebihara L (2006) Role of the $\mathrm{N}$-terminus in permeability of chicken connexin 45.6 gap junctional channels. J Physiol 576:787-799. doi:10.1113/jphysiol. 2006.113837

Ebihara L (1992) Expression of gap junction proteins in Xenopus oocyte pairs. Methods Enzymol 207:376-380

Ebihara L (1996) Xenopus connexin38 forms hemi-gap-junctional channels in the nonjunctional plasma membrane of Xenopus oocytes. Biophys J 71:742-748. doi:10.1016/S0006-3495(96)79273-1

Ebihara L (2003) New roles for connexons. News Physiol Sci 18:100-103. doi:10.1152/nips.01431.2002

Ebihara L, Tong JJ, Vertel B, White TW, Chen TL (2011) Properties of connexin 46 hemichannels in dissociated lens fiber cells. Invest Ophthalmol Vis Sci 52:882-889. doi:10.1167/iovs.106200

Gong X, Li E, Klier G, Huang Q, Wu Y, Lei H, Kumar NM, Horwitz J, Gilula NB (1997) Disruption of $a_{3}$ connexin gene leads to proteolysis and cataractogenesis in mice. Cell 9161:833-843

John SA, Kondo R, Wang SY, Goldhaver JI, Weiss JN (1999) Connexin-43 hemichannels opened by metabolic inhibition. J Biol Chem 274:236-243

Kalantan H (2012) Posterior polar cataract: a review. Saudi J Ophthalmol 26:41-49. doi:10.1016/j.sjopt.2011.05.001

Kronengold J, Trexler EB, Bukauskas FF, Bargiello TA, Verselis VK (2003) Single-channel SCAM identifies pore-lining residues in the first extracellular loop and first transmembrane domains of Cx46 hemichannels. J Gen Physiol 122:389-405. doi:10.1085/ jgp. 200308861

Maeda S, Nakagawa S, Suga M, Yamashita E, Oshima A, Fujiyoshi Y, Tsukihara T (2009) Structure of the connexin 26 gap junction channel at $3.5 \AA$ resolution. Nature 458:597-602. doi:10.1038/ nature 07869

Marziano NK, Casalotti SO, Portelli AE, Becker DL, Forge A (2003) Mutations in the gene for connexin 26 (GJB2) that cause hearing 
loss have a dominant negative effect on connexin 30. Hum Mol Genet 12:805-812. doi: $10.1093 / \mathrm{hmg} / \mathrm{ddg} 076$

Mathias RT, White TW, Gong X (2010) Lens gap junctions in growth, differentiation, and homeostasis. Physiol Rev 90:179-206. doi:10.1152/physrev.00034.2009

Mhaske PV, Levit NA, Li L, Wang HZ, Lee JR, Shuja Z, Brink PR, White TW (2013) The human Cx26-D50A and Cx26-A88V mutations causing keratitis-ichthyosis-deafness syndrome display increased hemichannel activity. Am J Physiol Cell Physiol 304:C1150-C1158. doi:10.1152/ajpcell.00374.2012

Minogue PJ, Liu X, Ebihara L, Beyer EC, Berthoud VM (2005) An aberrant sequence in a connexin 46 mutant underlies congenital cataracts. J Biol Chem 280:40788-40795. doi:10.1074/jbc. M504765200

Minogue PJ, Tong JJ, Arora A, Russell-Eggitt I, Hunt DM, Moore AT, Ebihara L, Beyer EC, Berthoud VM (2009) A mutant connexin50 with enhanced hemichannel function leads to cell death. Invest Ophthalmol Vis Sci 50:5837-5845. doi:10.1167/ iovs.09-3759

Oh S, Abrams CK, Verselis VK, Bargiello TA (2000) Stoichiometry of transjunctional voltage-gating polarity reversal by a negative charge substitution in the amino terminus of a connexin 32 chimera. J Gen Physiol 116:13-31

Oh S, Verselis VK, Bargiello TA (2008) Charges dispersed over the permeation pathway determine the charge selectivity and conductance of a $\mathrm{Cx} 32$ chimeric hemichannel. J Physiol 586:2445-2461. doi:10.1113/jphysiol.2008.150805

Pal JD, Berthoud VM, Beyer EC, Mackay D, Shiels A, Ebihara L (1999) Molecular mechanism underlying a Cx50-linked congenital cataract. Am J Physiol 276:C1443-C1446

Pal JD, Liu X, Mackay D, Shiels A, Berthoud VM, Beyer EC, Ebihara L (2000) Connexin46 mutations linked to congenital cataract show loss of gap junction channel function. Am J Physiol 279:C596-C602

Purnick PE, Benjamin DC, Verselis VK, Bargiello TA, Dowd TL (2000) Structure of the amino terminus of a gap junction protein. Arch Biochem Biophys 381:181-190

Ren Q, Riquelme MA, Xu J, Yan X, Nicholson BJ, Gu S, Jiang JX (2013) Cataract-causing mutation of human connexin 46 impairs gap junction, but increases hemichannel function and cell death. PLoS One 8:e74732. doi:10.1371/journal.pone.0074732

Rong P, Wang X, Niesman I, Wu Y, Benedetti LE, Dunia I, Levy E, Gong X (2002) Disruption of Gja8 (alpha8 connexin) in mice leads to microphthalmia associated with retardation of lens growth and lens fiber maturation. Development 129:167-174

Sáez JC, Schalper KA, Retamal MA, Orellana JA, Shoji KF, Bennett MVL (2010) Cell membrane permeabilization via connexin hemichannels in living and dying cells. Exp Cell Res 316:2377-2389. doi:10.1016/j.yexcr.2010.05.026

Santhiya ST, Kumar GS, Sudhakar P, Gupta N, Klopp N, Illig T, Soker T, Groth M, Platzer M, Gopinath PM, Graw J (2010) Molecular analysis of cataract families in India: new mutations in the CRYBB2 and GJA3 genes and rare polymorphisms. Mol Vis $16: 1837-1847$

Thomas BC, Minogue PJ, Valiunas V, Kanaporis G, Brink PR, Berthoud VM, Beyer EC (2008) Cataracts are caused by alterations of a critical N-terminal positive charge in connexin50. Invest Ophthalmol Vis Sci 49:2549-2556. doi:10.1167/ iovs.07-1658

Tong JJ, Ebihara L (2006) Structural determinants for the differences in voltage gating of chicken Cx56 and Cx45.6 gap-junctional hemichannels. Biophys J 91:2142-2154. doi:10.1529/biophysj. 106.082859

Tong JJ, Liu X, Dong L, Ebihara L (2004) Exchange of gating properties between rat $\mathrm{Cx} 46$ and chicken Cx45.6. Biophys J 8761:2397-2406. doi:10.1529/biophysj.104.039594

Tong JJ, Sohn BC, Lam A, Walters DE, Vertel BM, Ebihara L (2013) Properties of two cataract-associated mutations located in the NH2 terminus of connexin 46. Am J Physiol Cell Physiol 304:C823-C832. doi:10.1152/ajpcell.00344.2012

Trexler EB, Bukauskas FF, Kronengold J, Bargiello TA, Verselis VK (2000) The first extracellular loop domain is a major determinant of charge selectivity in connexin46 channels. Biophys J 79:3036-3051. doi:10.1016/S0006-3495(00)76539-8

VanSlyke JK, Deschenes SM, Musil LS (2000) Intracellular transport, assembly, and degradation of wild-type and disease-linked mutant gap junction proteins. Mol Biol Cell 11:1933-1946

Verselis VK, Ginter CS, Bargiello TA (1994) Opposite voltage gating polarities of two closely related connexins. Nature 368:348-351

White TW, Goodenough DA, Paul DL (1998) Targeted ablation of connexin50 in mice results in microphthalmia and zonular pulverulent cataracts. J Cell Biol 143:815-825. doi:10.1083/jcb. 143.3.815

Xu X, Ebihara L (1999) Characterization of a mouse Cx50 mutation associated with the No2 mouse cataract. Invest Ophthalmol Vis Sci 40:1844-1850 